\title{
Cardiopulmonary Bypass Management Complicated by a Stenotic Coronary Sinus and Cold Agglutinins
}

\author{
Suraj Yalamuri, $\mathrm{MD}^{*, 1}$, Michele Heath, $\mathrm{CCP}^{\dagger}$, \\ Sharon McCartney, MD*, Tera Cushman, MD*, \\ Cory Maxwell, $\mathrm{MD}^{\ddagger}$ \\ *Duke University Medical Center, Department of Anesthesiology, Durham, NC \\ ${ }^{\dagger}$ Durham VA Medical Center, Durham, NC \\ ${ }^{\ddagger}$ Duke University Medical Center, Department of Anesthesiology, Divisions of Cardiothoracic \\ Anesthesiology and Veteran Affairs Anesthesiology, Durham, NC
}

COLD AGGLUTININS (CA) are circulating autoantibodies that reversibly bind red blood cells, causing agglutination and increased blood viscosity. ${ }^{1}$ Because cardiopulmonary bypass (CPB) can involve deliberate hypothermia of the systemic and coronary circulations, the adverse sequelae of CA have been feared and reported under such conditions. The authors present a case of successful perioperative management of a patient in whom $\mathrm{CA}$ activation was diagnosed after the initiation of CPB for coronary artery bypass grafting $(\mathrm{CABG})$ and aortic valve replacement (AVR). This patient also had a stenotic coronary sinus (CS), adding to the complexity of management of $\mathrm{CPB}$ and administration of cardioplegia. Patient permission was obtained for the publication of this case report.

\section{Description}

A 67-year-old man with moderate-to-severe aortic stenosis (mean gradient $36 \mathrm{~mm} / \mathrm{s}$ ) and multivessel coronary artery disease presented for CABG and AVR. Preoperative workup revealed preserved biventricular function with moderate left ventricular hypertrophy, $80 \%$ stenosis of the proximal left main coronary artery, and $99 \%$ stenosis of the proximal right coronary artery. He previously underwent an uneventful anesthetic for carotid artery bypass in preparation for his cardiac surgery. After placement of a radial artery catheter for

\footnotetext{
${ }^{1}$ Address reprint requests to Suraj Yalamuri, MD, Duke University Medical Center, Department of Anesthesiology, DUMC 3094, Durham, NC 27710.

E-mail address: Suraj.Yalamuri@duke.edu (S. Yalamuri).
}

pressure monitoring, anesthesia was induced with midazolam, fentanyl, lidocaine, propofol, and rocuronium. Aminocaproic acid was used for antifibrinolysis, with a 10-g bolus dose followed by a 5-g dose infused over 5 hours. Vein graft harvest and central aortic arterial and bicaval venous cannulation were uneventful.

After an activated coagulation time of $>400$ seconds was achieved, CPB was initiated. Because of CS stenosis (confirmed by the small ostial opening on transesophageal echocardiography [TEE]), a retrograde catheter could not be placed even under direct vision with bicaval cannulation (performed for better visualization of the coronary sinus ostia after the initial inability to cannulate). ${ }^{2}$ Systemic perfusion was maintained at $36^{\circ} \mathrm{C}$ inflow temperature, and the nasopharyngeal temperature approached a nadir of $35^{\circ} \mathrm{C}$.

Before administration of cardioplegia, crystalloid cardioplegic solution (Plegisol; Hospira, Lake Forest, IL) was mixed with blood ( $4: 1$ ratio) and cooled to $4 \mathrm{C}$ with a BCD Vanguard heat exchanger (Sorin, Milan, Italy). Within the tubing the blood separated rapidly, and large clumps of red cells were seen settling through the plasma in the tubing (Fig 1, Video 1). Because of the high index of suspicion, no cardioplegia was given, pending laboratory confirmation. A sample of blood was sent to the laboratory immediately for a rapid test for cold agglutinins. Specific cold agglutinin testing was not available immediately; however, a small amount of blood was cooled to $4^{\circ} \mathrm{C}$, and $4+$ agglutination was observed. This information was relayed to the operating room so that the surgical plan could be altered. Subsequent testing revealed $2+$ agglutination at $10^{\circ} \mathrm{C}$ 


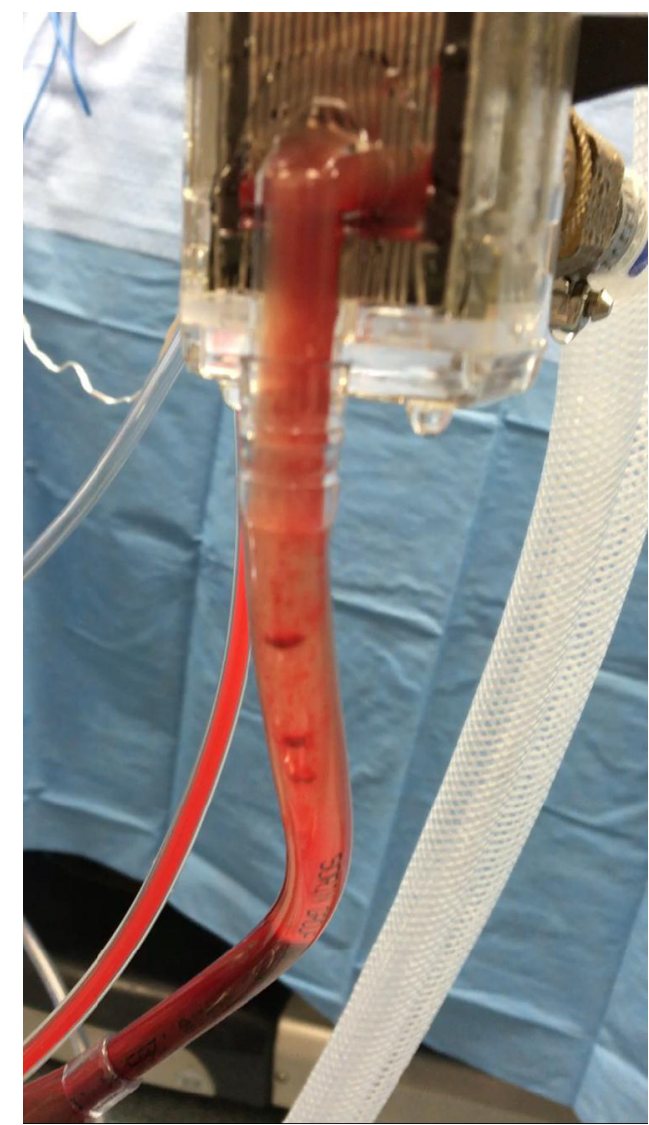

Fig. 1. Clumps of red cells in the tubing underneath the cardioplegia heat exchanger.

and no agglutination at room temperature. The patient's initial thermal threshold was $15^{\circ} \mathrm{C}$. On his follow-up postoperative visit, he was noted to have only weak reactivity at $4^{\circ} \mathrm{C}$.

The cardioplegia system was flushed thoroughly and cardiac arrest was achieved with antegrade $4^{\circ} \mathrm{C}$ crystalloid-only cardioplegia. All maintenance cardioplegia was given as cold crystalloid only. Maintenance doses were given antegrade every 20 minutes. Only 2 distal targets were viable and able to be grafted. Electromechanical silence was achieved and maintained throughout the entire cross-clamp period, with a myocardial temperature of $10.8^{\circ} \mathrm{C}$ before myocardial rewarming. Prior to cross-clamp removal, warm crystalloid-only cardioplegia was administered while monitoring myocardial temperature to prevent further agglutination.

After separation from CPB, the prosthetic valve was well seated with no leak and normal gradient. Biventricular function was preserved with no regional wall motion abnormalities. Postoperatively, the patient's temperature was maintained above $36^{\circ} \mathrm{C}$ and no cold fluids were administered. There were no postoperative neurologic deficits and no further agglutination events.

\section{Discussion}

Cardioplegia provides a noncontracting heart and a field without blood; it is the preferred method of myocardial protection during myocardial ischemia. ${ }^{3}$ Inadequate myocardial protection can have postoperative consequences, such as myocardial infarction, low-cardiac-output state, the need for ionotropic support to wean the patient from CPB, and stroke. ${ }^{4}$ In addition, the combination of cold agglutination and complement activation can lead to significant hemolysis.

A multitude of cardioprotective strategies can be used to obtain the desired result based on the cardiac surgery. In a typical CABG and AVR surgery, antegrade cardioplegia is given intermittently, but direct ostial or retrograde delivery of cardioplegia is necessary while the aorta is open to replace the aortic valve. The ideal management for $\mathrm{CA}$ diagnosed preoperatively is to give warm continuous blood or intermittent warm blood cardioplegia every 15 to 20 minutes during the cross-clamp period..$^{5-7}$ In isolated CABG surgery, this can be accomplished via continuous antegrade cardioplegia. However, because AVR requires an aortotomy, continuous warm blood cardioplegia typically would be given retrograde through the coronary sinus. In this patient, the stenotic CS prevented myocardial protection via the retrograde route. Echocardiographic measurement of the coronary sinus ostia was $4.3 \mathrm{~mm}$ with no visible valvular structure on TEE. This was smaller than the reported values and explained the inability to cannulate, although a valve not seen on TEE was possible.

The new diagnosis of CA complicated planning for alternative cardioplegia administration. Cold agglutination phenomenon is rare in the clinical arena, but the incidence is increased in cardiac surgery because of the routine use of hypothermia while on CPB. Complications after CA activation can include cerebral insult, ischemia due to microvascular occlusion, hemolysis, and renal and hepatic dysfunction. ${ }^{8}$ In this patient, agglutination causing obstruction of the coronary circulation was a feared complication. Appropriate screening with CA titers and thermal threshold has been recommended for patients undergoing cardiac surgery who are suspected to be at risk. ${ }^{1}$ However, the incidence of cold agglutination syndrome was found to be $0.3 \%$ among 14,900 patients undergoing cardiac surgery with $\mathrm{CPB}$ who were all screened with CA titers. Jain et al reported that the surgeons altered cardiopulmonary bypass management by avoiding hypothermia in only one-third of the identified patients. ${ }^{9}$

Because most cardiac patients are not screened for cold agglutinins preoperatively, prompt detection upon initiation of $\mathrm{CPB}$ is useful to properly plan and avoid harm. The perfusionist's priming of the cold cardioplegia system with blood as soon as possible provides the longest window for CA detection before the aortic cross-clamp is applied and cold cardioplegia is administered. ${ }^{10}$ Moreover, because continuous warm blood was not feasible in this patient because of the AVR, cold crystalloid was the only option. ${ }^{11}$ Additionally, for cold agglutinins, in one single-center study, stroke, myocardial infarction, dialysis, low-output syndrome, sepsis, and deep vein thrombosis were measured at $14.9 \%$ in those with $\mathrm{CA}$ versus $9.2 \%$ for those without. ${ }^{9}$ Although $\mathrm{CA}$ is a feared complication of $\mathrm{CPB}$, it can be managed successfully with no increases in overall morbidity or mortality. 


\section{Conclusion}

Although CPB presents many challenges, they routinely are managed successfully with well-developed techniques. However, technical challenges continue to arise and the multitude of techniques that rely on redundancy and flexibility allowed for the successful management of this case without complications.

\section{Appendix A. Supplementary material}

Supplementary data associated with this article can be found in the online version at http://dx.doi.org/10.1053/j.jvca.2016.03.130.

\section{References}

1 Barbara DW, Mauermann WJ, Neal JR, et al. Cold agglutinins in patients undergoing cardiac surgery requiring cardiopulmonary bypass. J Thorac Cardiovasc Surg 2013;146:668-80.

2 Menasche P, Subayi JB, Piwnica A. Retrograde coronary sinus cardioplegia for aortic valve operations: A clinical report on 500 patients discussion 563-554. Ann Thorac Surg 1990;49:556-63.
3 Buckberg GD. Update on current techniques of myocardial protection. Ann Thorac Surg 1995;60:805-14.

4 Durandy YD. Is there a rationale for short cardioplegia re-dosing intervals? World J Cardiol 2015;7:658-64.

5 Aoki A, Kay GL, Zubiate P, et al. Cardiac operation without hypothermia for the patient with cold agglutinin. Chest 1993;104:1627-9.

6 Miyaki Y, Takagi N, Hasegawa T, et al. Aortic valve surgery in a patient with cold agglutinin disease; effectiveness of continuous retrograde cardioplegia. Kyobu Geka 2013;66:187-9.

7 Atkinson VP, Soeding P, Horne G, et al. Cold agglutinins in cardiac surgery: Management of myocardial protection and cardiopulmonary bypass. Ann Thorac Surg 2008;85:310-1.

8 Hoffman Jr JW, Gilbert TB, Hyder M. Cold agglutinins complicating repair of aortic dissection using cardiopulmonary bypass and hypothermic circulatory arrest: Case report and review. Perfusion 2002;17:391-4.

9 Jain MD, Cabrerizo-Sanchez R, Karkouti K, et al. Seek and you shall find -but then what do you do? Cold agglutinins in cardiopulmonary bypass and a single-center experience with cold agglutinin screening before cardiac surgery. Transfus Med Rev 2013;27:65-73.

10 Dake SB, Johnston MF, Brueggeman P, et al. Detection of cold hemagglutination in a blood cardioplegia unit before systemic cooling of a patient with unsuspected cold agglutinin disease. Ann Thorac Surg 1989;47:914-5.

11 Izzat MB, Rajesh PB, Smith GH. Use of retrograde cold crystalloid cardioplegia in a patient with unexpected cold agglutination. Ann Thorac Surg 1993;56:1395-7. 